\title{
NUTRITIONAL EFFECT OF ALPHA-LINOLENIC ACID ON HONEY BEE COLONY DEVELOPMENT (APIS MELLIFERA L.)
}

\author{
Lanting Ma \\ Ying Wang \\ Xiaobo Hang \\ Hongfang Wang \\ Weiren Yang \\ Baohua Xu* \\ College of Animal Science and Technology, Shandong Agricultural University, \\ Daizong Road No.61, Shandong 271000 Tai' an, China \\ *corresponding author: bhxu@sdau.edu.cn \\ Received 01 February 2015; accepted 09 November 2015
}

\begin{abstract}
Alpha-linolenic acid (ALA), which is an n-3 polyunsaturated fatty acid (PUFA), influences honey bee feed intake and longevity. The objective of this study was to research the effect of six dietary ALA levels on the growth and development of Apis mellifera ligustica colonies. In the early spring, a total of $\mathbf{3 6}$ honey bee colonies of equal size and queen quality were randomly allocated into 6 groups. The six groups of honey bees were fed a basal diet with supplementation of ALA levels at 0 (group A), 2 (group B), 4 (group C), 6 (group D), 8 (group E), and 10\% (group F). In this study, there were significant effects of pollen substitute ALA levels on the feeding amounts of the bee colony, colony population, sealed brood amount, and weight of newly emerged workers $(P<0.05)$. The workers' midgut Lipase (LPS) activity of group $C$ was significantly lower than that of the other groups $(P<0.01)$. The worker bees in groups $B, C$, and $D$ had significantly longer lifespans than those in the other groups $(P<0.05)$. However, when the diets had ALA concentrations of more than $6 \%$, the mortality of the honey bees increased $(P<0.01)$. These results indicate that ALA levels of $2 \sim 4 \%$ of the pollen substitute were optimal for maintaining the highest reproductive performance and the digestion and absorption of fatty acids in honey bees during the period of spring multiplication. Additionally, ALA levels of $2 \sim 6 \%$ of the pollen substitute, improved worker bee longevity.
\end{abstract}

Keywords: alpha-linolenic acid, Apis mellifera ligustica, colonies development, digestive enzyme, feeding trial, longevity.

\section{INTRODUCTION}

Nutrients are the components in foods which an organism utilises to live. Honey bees obtain nutrients mainly from pollen (Pirk et al., 2009), which supplies the bees with protein, sugars, vitamins, minerals etc. Pollen is also the principal source of lipids for the bees. Nutrients sustain the rapid growth of larvae and the completion of development within the first few days after the bees' emergence (De Groot, 1953; Herbert and Shimanuki, 1978a; Pernal and Currie, 2000; Manning, 2001). But during early spring, pollen stores in the hive often become depleted before more resources can be gathered in the environment (Farrar, 1934). When bees do not have access to pollen, they can utilise their protein for brood rearing until their protein content drops to
$20 \%$ of their body weight (Black, 2006). At the same time, the queen bee stops laying eggs, and the colony population weakens (Manning et al., 2007). In this case, the colony may be offered a pollen substitute, which is food intended to completely replace pollen. Food sources for use as pollen substitutes, for these occasions, have been studied for many years. The most widely used substitute consists of a mixture of soybean flour, corn flour, and dried brewers' yeast (House, 1961; Jouanin, 2000; Feng, 2002; Saffari et al., 2004). These substitutes are fed to colonies to maintain or increase their populations, and the hope is that such pollen substitutes do not adversely influence the quality of larval food produced nor have any deleterious influence on the activity of the digestive enzymes of the bees' midgut.

Sahiler et al. (2003) indicated that feeding bees with 
a combination of pollen substitute and sugar syrup causes a much higher increase in the numbers of bees and frames covered by bees, the brood area, and the colony weight, compared with feeding sugar syrup or pollen alone. Nutrition is not only important for colony development and bee longevity but also plays a vital role against pathogens and in maintaining gut fitness (Ritz and Gardner, 2006; Steen, 2007). In recent years, though, various pollen substitutes have been advocated and become commercially available, and most of these substitutes appear to be either nutritionally poor or unpalatable, and not well-tested (Saffari et al., 2004). The factors that influence the nutrition and palatability of pollen substitutes include the amounts of protein and lipids that these substitutes contain (De Groot, 1953; Schmidt et al., 1987).

For honey bees, protein is the most important macro-nutrient of pollen substitutes because it is largely used to feed developing larvae and young bees to provide the structural elements of muscles, glands, and other tissues (De Groot, 1953; Herbert and Shimanuki, 1978a; Afik et al., 2006). Information regarding the protein and amino acid requirements of honey bee colonies and individuals, is plentiful (De Groot, 1953; Barker and Lehner, 1972; Kim and Smith, 2000; Afik et al., 2006; Weiner et al., 2010; Hendriksma et al., 2014; Paoli et al., 2014), but data regarding lipid or fatty acid requirements are scarce. Nevertheless, lipids, among then fatty acids, play an important role in the honey bee diet (Loidl and Crailsheim, 2001; Manning et al., 2007).

In general, linolenic acid (C18:3), linoleic acid (C18:2), and palmitic acid (C16:0) predominate in pollen, and the proportion of them is roughly 1.0: 0.65: 0.83 (Saa-Otero et al., 2000; Manning, 2001; Manning et al., 2007). Alpha-linolenic acid (ALA) is an n-3 polyunsaturated fatty acid (PUFA). Alpha-linolenic acid is essential for life because this PUFA is an essential component of cellular membranes and biological enzymes, and is also the prerequisite material for eicosapentaenoic acid (EPA) and docosahexaenoic acid (DHA) (Kinsella, 1991). The addition of some unsaturated fatty acids in pollen substitutes, is beneficial for the growth and development of insects (Nation, 2001).

We know little regarding the nutritional effects of ALA. In order to systematically evaluate the nutritional effects of ALA on honey bees, this study examined the colony development, bee longevity, and midgut digestive enzyme activity.

\section{MATERIAL AND METHODS}

\section{Experimental design and feeding diet}

The experiment was conducted in one apiary in Tai'an, Shandong Province, China $\left(35^{\circ} 38^{\prime} \mathrm{N}, 116^{\circ} 02^{\prime} \mathrm{E}\right)$. Thirty-six colonies of bees with sister queens from the same breeding line, were randomly allocated into six groups. The control group was fed a basal diet (group A) in which no ALA was added. The other five groups were fed diets with supplemented ALA levels at 2\% (group B), 4\% (group C), 6\% (group D), $8 \%$ (group $E$ ), and $10 \%$ (group $F$ ). The basal diet (Tab. 1) was a mixture of corn meal, soybean meal, and brewer's yeast. All of these ingredients were processed into particles which were $0.15 \mathrm{~mm}$ in size (Somerville, 2000). The other ingredients of the basal diet included: sucrose, sodium citrate, choline chloride, and calcium carbonate. Enough water was added to make a moist patty. During this study, the colonies were checked every 3 days to make sure each colony had an adequate dietary supply. The trial period was 50 days, in which the pre-feeding period was 14 days, and the positive test was 36 days.

\section{Feeding regimes and estimates of consumption}

Colonies were fed diets in patty form. Patties were all wrapped with a plastic film at the top to reduce the water loss. The pre-weighed patty for each colony was flattened between sheets of waxed paper and placed weekly on the top of the frames over the brood cluster (Li et al., 2012). After feeding the colonies, the unconsumed portions of the patty diets were removed from the colony and weighed to estimate consumption. The bees had access to water and the patty ad libitum. Pollen traps were used during the experimental time to keep the bees away from other pollen sources. The data used for the statistical analysis were the diet consumption and total lipids consumption during the positive test.

\section{Brood and adult worker bee estimates}

Brood measurements were made every 12 days using a transparent plastic grid paper that had $5 \mathrm{~cm} \times 5 \mathrm{~cm}$ squares that covered the entire side of a comb. The number of squares with broods was counted. Measurements of all frames with broods were made for each colony to a total area, and then the colony brood was obtained using the conversion factor 4.29 bee $/ \mathrm{cm}^{2}$ (Seeley and Visscher, 1985). Adult bee populations were also measured every 12 days by estimating the number and area of the comb covered with bees. We totaled the area covered 
Basal diet formulation and compositions (\%)

Table 1.

\begin{tabular}{|c|c|}
\hline Item & Percentage (\%) \\
\hline \multicolumn{2}{|l|}{ Ingredients: } \\
\hline Corn & 20.09 \\
\hline Brewer's yeast & 4.79 \\
\hline Soybean meal & 40.19 \\
\hline Sucrose & 33.32 \\
\hline Antioxidant ${ }^{1}$ & 0.09 \\
\hline Fungicide $^{1}$ & 0.02 \\
\hline Premix ${ }^{2}$ & 0.30 \\
\hline Sodium citrate & 0.48 \\
\hline Choline chloride & 0.48 \\
\hline Calcium carbonate & 0.24 \\
\hline Total: & 100.00 \\
\hline \multicolumn{2}{|l|}{ Nutrient levels: } \\
\hline Gross Energy (MJ'kg-1) & 17.05 \\
\hline Crude fat & 1.61 \\
\hline Crude protein & 21.26 \\
\hline Alpha-linoleic acid ${ }^{3}$ & 0.03 \\
\hline Calcium & 0.35 \\
\hline Phosphorus & 0.26 \\
\hline
\end{tabular}

${ }^{1}$ Antioxidant and fungicide were used to prevent the powder from deteriorating in the summer. Propanoic acid sodium salt was used as the fungicide, low toxicity.

${ }^{2}$ The premix provided (per kg of diet): vitamin A, 5000 IU; B1,7.5 mg; B2,6.8 mg; C, $303.2 \mathrm{mg} ;$ E, $240 \mathrm{mg}$;

D, 2000 IU; B6,13 mg; niacin, 24 mg; folic acid, 20 mg; and inositol, 500 mg.

${ }^{3}$ The values of alpha-linoleic acid was measured by the meteorological chromatographic of GC-2014.

with bees for all frames to estimate the number of frames in the colony covered with bees, represented by "full frame bees" (Wang et al., 2011).

\section{Emergence weight of worker bees}

When putting an empty honeycomb into each beehive after 21 days, ten worker bees were collected at the point of emergence directly from their capped cells, weighed, and put into a $7 \mathrm{~mL}$ centrifuge tube. The bees were then weighed again using an electronic balance (precision: $0.1 \mathrm{mg}$ ). This procedure was repeated three times for each colony, and the averages were used for the statistical analysis.

\section{Determination of honey bee longevity}

Twenty-four wooden cages $(40 \mathrm{~mm}$ width $\times 200 \mathrm{~mm}$ length $\times 60 \mathrm{~mm}$ height, with a perforated transparent plastic cover) were built and provided with a small piece of bee comb. During the late stage of the feeding trial, newly emerged workers from each treatment group were captured separately and put into 4 cages. Each cage contained about 200 bees, which were fed the corresponding pollen substitutes for each treatment group. The cages were incubated at $33 \pm 0.5^{\circ} \mathrm{C}$ with a relative humidity between 50 and $60 \%$. The pollen substitutes, the sugar syrup (sugar: water $=1: 1$ ), and clean water were checked every day and replenished in gravity feeders as needed. After the first day, the dead bees were removed from the floor of each cage, and then the dead bees were counted and removed every five days. We conducted a statistical analysis on the $30^{\text {th }}$ day of survival.

\section{Determination of digestive enzyme activity in} the midgut of worker bees

One hundred newly emerged workers from each colony were marked with paint on their thorax. From each colony, 30 marked bees were obtained seven days after emergence (Li et al., 2012). The 
worker bees were first cold-anesthetized. Then, the midguts, which were analyzed for digestive enzyme activities were isolated by dissection.

Ten midguts as one sample were homogenized with saline $(0.9 \%$ solution $\mathrm{w} / \mathrm{v})$ at a ratio of $1: 4$ $(W / V)$ for $30 \mathrm{~s}$. Then, the mixture were centrifuged at $5000 \mathrm{rpm}$ for $10 \mathrm{~min}$ at $4^{\circ} \mathrm{C}$, and an aliquot of the supernatant was used to determinate three kind of digestive enzyme activity: lipase, amylase and sucrase. Lipase (LPS, A054), amylase (AMS, C016) and sucrase (Sucrase, A082-2) assay kits were purchased from the Institute of Biological Engineering of Naijing Jiancheng, Nanjing, China. The procedure was repeated three times for each colony, and the average was used for the statistical analysis.

\section{Data calculation and statistical analysis}

All data were subjected to one-way ANOVA using the GLM procedure of SAS software (SAS 9.1, 2003). $\mathrm{P}<0.05$ was considered statistically significant.

\section{RESULTS}

\section{Substitute diet consumption}

The colonies typically consumed more than $350 \mathrm{~g}$ of the pollen substitute diets (dry matter) during each 3-week-interval (Tab. 2). The substitute diet consumption of group $C$ was similar to group $B$, whereas this consumption was significantly greater than group $D$, group $E$, and group $F(P<0.05)$. Although the diet consumption of group $F$ was the lowest of all of the treatments, the total lipid consumption levels of groups $F$ and $E$ were significantly greater than those of the other treatments $(P<0.05)$, successively followed by groups $D, C, B$, and $A$ (the control).

\section{Brood and adult worker bees}

The average number of sealed brood cells and the adult population size at the beginning of the study were the same among the groups of colonies. After 12 days, the colonies had an average of 2.10 frames of adult bees and $3.15 \times 10^{3}$ sealed brood cells. The adult bee populations increased during the following 24 days and 36 days. The populations of groups $B$, $C$, and $D$ were significantly greater than those of the control group, and groups $E$ and $F(P<0.05)$. Only the 24 days sealed brood cell groups were significantly affected by the pollen substitute diet, and group $C$ had more brood than the other groups $(P<0.05)$. Although no significant difference in sealed brood cells was observed at 36 days, the colonies had more than twice the brood size at 36 days than at 12 days (Tab. 3 and 4 ).

\section{Emergence weight of worker bees}

The pollen substitute diet significantly affected the weight of emergent worker bees $(P<0.01)$ (Fig. 1).

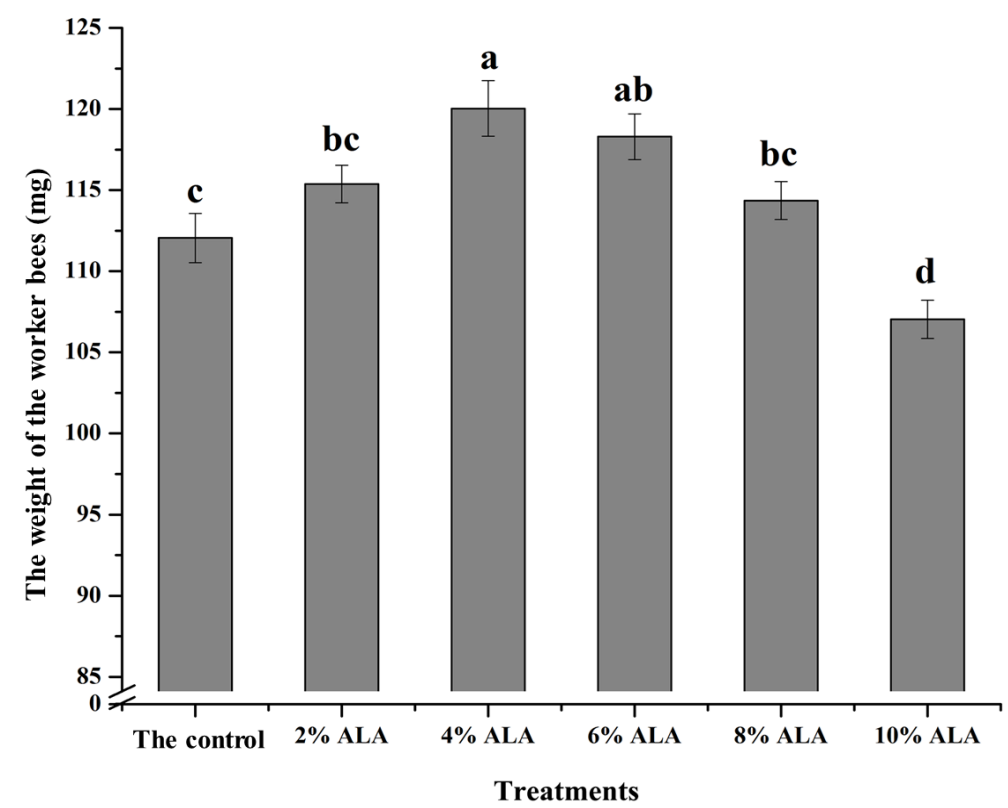

Fig. 1. The average weight of emergent worker bees \pm SE. Relative to the control group, in which there was no extra alpha-linolenic acid (ALA) added, the emergent worker bee weights of $4 \%$ ALA group and $6 \%$ ALA group were increased by $7.12 \%$ and $5.57 \%$, respectively. Each treatment had six replicates. Different letters above bars within the same species indicate significant differences (generalised linear models with false discovery rate correction, $\mathrm{P}<0.05$ ). 
Table 2.

Diet (on a dry matter basis) and lipid intake of honey bees from colonies fed pollen substitutes

$(\mathrm{N}=6$ colonies per treatment)

\begin{tabular}{cccc}
\hline Groups & $\begin{array}{c}\text { ALA levels } \\
\text { (\%) }\end{array}$ & $\begin{array}{c}\text { Diet consumption } \\
\text { (g/colony) }\end{array}$ & $\begin{array}{c}\text { Total lipid consumption } \\
\text { (g/colony) }\end{array}$ \\
\hline A & 0 & $396.87 \pm 21.25 \mathrm{bc}$ & $11.79 \pm 0.63 \mathrm{~d}$ \\
B & 2 & $433.27 \pm 10.10 \mathrm{ab}$ & $21.27 \pm 0.50 \mathrm{c}$ \\
C & 4 & $465.70 \pm 16.98 \mathrm{a}$ & $32.83 \pm 1.20 \mathrm{bc}$ \\
D & 6 & $396.83 \pm 15.16 \mathrm{bc}$ & $35.80 \pm 2.07 \mathrm{bc}$ \\
E & 8 & $379.00 \pm 17.00 \mathrm{c}$ & $41.77 \pm 1.87 \mathrm{a}$ \\
F & 10 & $355.00 \pm 8.91 \mathrm{c}$ & $45.62 \pm 1.14 \mathrm{a}$ \\
\hline P-value (linear) & & 0.002 & $<0.0001$ \\
\hline
\end{tabular}

Data were analysed by the generalised linear models using treatment as a fixed factor, and parameter as a dependent variable. The same column with different letters mean significant differences $(P<0.05)$, while the same letters mean no significant differences $(P>0.05)$.

Population from colonies fed pollen substitutes ( $N=6$ colonies per treatment)

Table 3.

\begin{tabular}{ccccc}
\hline \multirow{2}{*}{ Groups } & \multirow{2}{*}{ ALA levels (\%) } & \multicolumn{2}{c}{ Population of bee colony (number of frames) } \\
\cline { 3 - 5 } & & $\mathbf{1 2}$ days & 24 days & 36 days \\
\hline $\mathrm{A}$ & 0 & $2.10 \pm 0.03$ & $3.77 \pm 0.32 \mathrm{~b}$ & $4.74 \pm 0.28 \mathrm{c}$ \\
$\mathrm{B}$ & 2 & $2.05 \pm 0.03$ & $4.50 \pm 0.29 \mathrm{ab}$ & $5.80 \pm 0.12 \mathrm{ab}$ \\
$\mathrm{C}$ & 4 & $2.21 \pm 0.15$ & $5.00 \pm 0.35 \mathrm{a}$ & $6.08 \pm 0.32 \mathrm{a}$ \\
$\mathrm{D}$ & 6 & $2.28 \pm 0.24$ & $4.10 \pm 0.37 \mathrm{ab}$ & $5.73 \pm 0.33 \mathrm{~b}$ \\
$\mathrm{E}$ & 8 & $2.10 \pm 0.10$ & $3.84 \pm 0.32 \mathrm{~b}$ & $4.96 \pm 0.24 \mathrm{bc}$ \\
F & 10 & $1.88 \pm 0.12$ & $3.43 \pm 0.28 \mathrm{~b}$ & $4.93 \pm 0.43 \mathrm{~b}$ \\
\hline P-value (linear) & & 0.529 & 0.046 & 0.014 \\
\hline
\end{tabular}

Data were analysed by the generalised linear models using treatment as a fixed factor, and parameter as a dependent variable. The same column with different letters mean significant differences $(P<0.05)$, while the same letters mean no significant differences $(\mathrm{P}>0.05)$.

Table 4.

The number of sealed brood cells from colonies fed pollen substitutes ( $N=6$ colonies per treatment)

\begin{tabular}{ccccc}
\hline Groups & ALA levels (\%) & \multicolumn{3}{c}{ The number of sealed brood cells (103/hive) } \\
\cline { 2 - 5 } & & 12 days & 24 days & 36 days \\
\hline A & 0 & $3.30 \pm 0.39$ & $4.69 \pm 0.17 \mathrm{bc}$ & $6.49 \pm 0.45$ \\
B & 2 & $3.21 \pm 0.09$ & $5.19 \pm 0.29 \mathrm{ab}$ & $6.54 \pm 0.20$ \\
C & 4 & $3.47 \pm 0.41$ & $5.46 \pm 0.36 \mathrm{a}$ & $6.73 \pm 1.02$ \\
D & 6 & $3.28 \pm 0.22$ & $4.16 \pm 0.23 \mathrm{c}$ & $6.85 \pm 0.59$ \\
E & 8 & $3.12 \pm 0.37$ & $4.04 \pm 0.13 \mathrm{c}$ & $6.41 \pm 0.76$ \\
F & 10 & $2.54 \pm 0.33$ & $3.22 \pm 0.22 \mathrm{~d}$ & $6.29 \pm 0.19$ \\
\hline P-value (linear) & & 0.611 & $<0.001$ & 0.970 \\
\hline
\end{tabular}

Data were analysed by the generalised linear models using treatment as a fixed factor and parameter as a dependent variable. The same column with different letters mean significant differences $(P<0.05)$, while the same letters mean no significant differences $(P>0.05)$. 
The average weight of emergent worker bees in group C was the highest, at $120.03 \mathrm{mg}$, and displayed an increase of $7.12 \%$ over that of the control group (112.05 mg). In contrast, group F had the lowest weight, at $107.04 \mathrm{mg}$. Nonetheless, no significant differences were observed between groups $C$ and $D(P>0.05)$. the groups under the indoor rearing conditions $(P<0.05)$. Group $C$ had the highest life expectancy, and group $F$ had the lowest. Groups B, C, and D had longer lifespans than those of the control group and groups $E$ and $F$.

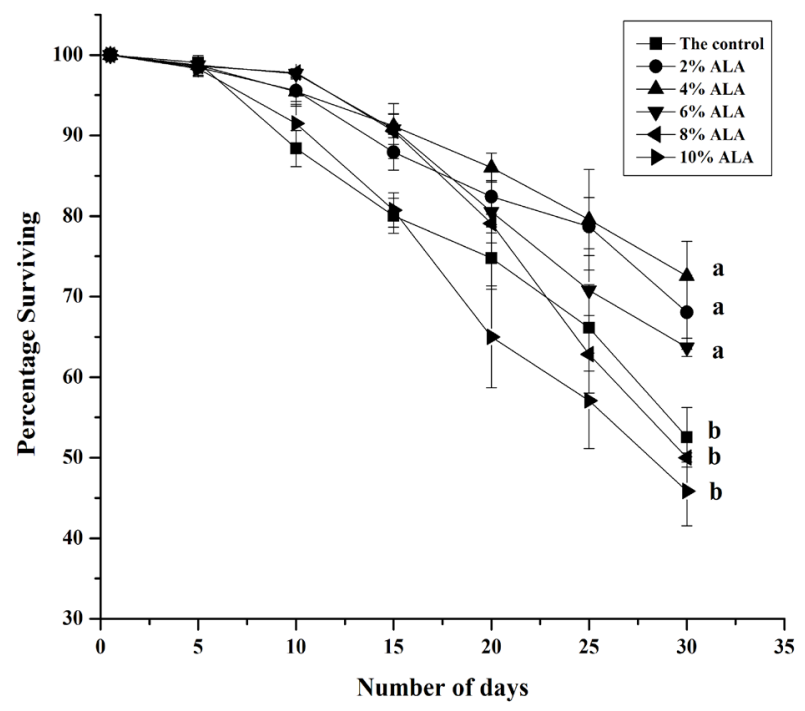

Fig. 2. Effect of alpha-linolenic acid (ALA) on worker bee survival. The different letters indicate significant differences $(P<0.05)$, while the same letters indicate no significant differences $(P>0.05)$.

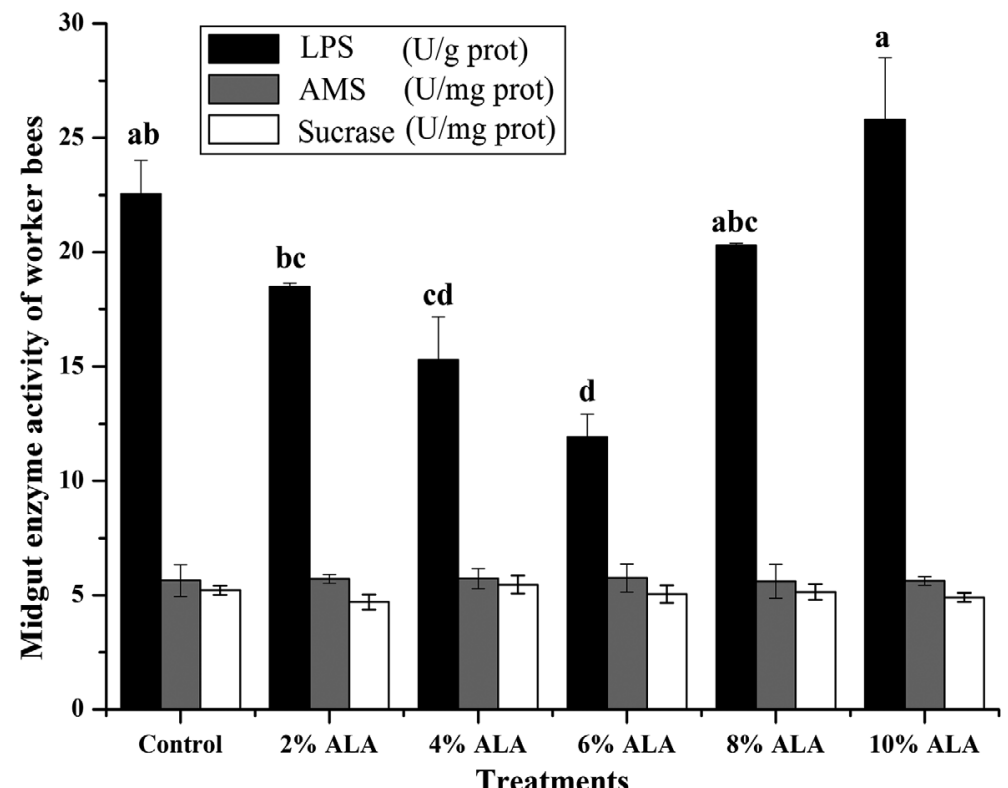

Fig. 3. Effect of alpha-linolenic acid (ALA) concentration on the lipase (LPS), amylase (AMS), and sucrose activity in the midgut of the worker bees. Different letters above bars within the same species indicate significant differences (generalised linear models with false discovery rate correction, $\mathrm{P}<0.05$ ).

\section{Worker bee longevity}

The effects of different concentrations of ALA on the lifespan of newly emerged workers are shown in Fig. 2. Honey bee longevity differed greatly between

\section{Digestive enzyme activity}

After the pollen substitute was consumed by the honey bees, it was primarily digested in the midgut of the honey bees. Thus, the digestive enzyme 60 
activity in the midgut may reflect the digestive ability of the bees. The lipase activity (LPS) in the honey bee midgut was sensitive to the ALA in the diet (Fig. 3). The lipase activity appeared to decrease after an initial trend, and then to increase between the treatment groups when increasing levels of ALA were added. The lipase activity was the highest in group $F$ and at a minimum for group D; the LPS activity levels of $C$ and $D$ were similar $(P>0.05)$. The amylase activity (AMS) and sucrase activity were not significantly different among the groups

\section{DISCUSSION}

The nutritional value of fatty acids for honey bees has not been completely explained, although some reports regarding the effect of fatty acids on two major honey bee pathogens have been published (Feldlaufer et al., 1983; Hornitzky, 2003). Nevertheless, some explanation regarding the nutritional value of fatty acids can be inferred and can be discussed.

This study showed that bees consumed significantly more ALA in pollen substitutes than in the control diet. The high consumption of ALA in pollen substitutes was most likely because the substitute with ALA was more attractive and palatable to the honey bees. Studies have shown that chemicals attractive to honey bees reside in the lipid fraction of the sticky covering found on the surface of pollen grains; the so-called pollenkitt (Dobson, 1988). However, in our study, when 4\% ALA was added to the pollen substitute, the diet consumption was higher for this group than for the other groups because this ALA level was the closest to the natural bee bread fatty acid content (Herbert and Shimanuki, 1978b).

For pollen and pollen substitutes to provide adequate nutrition for the bees, digestive enzymes play a role in the process of digestion and absorption of these nutrients. The in vivo digestive enzymes of bees include protease, lipase, amylase, invertase, and trehalase (Sudd, 1985). These enzymes are found in the bee intestine, which is the primary site of digestion. Chime (the semifluid mass of partly digested food) is also formed at the digestion and absorption sites (Standifer, 1980). Therefore, the determination of intestinal digestive enzyme activity can reflect, to some extent, the ability of bees to digest and absorb nutrients. In this experiment, the ALA levels did not have a significant effect on the amylase and invertase activity in the intestines of bees at 7 day, yet lipase activity had a significant effect. Lipase catalyses the hydrolysis of fats into glycerol and fatty acids. This hydrolysis plays an important role in fat metabolism in the medium term. Studies have shown that fatty acids can inhibit fatty acid synthase activity (Mersmann et al., 1973). In this experiment, successive lipase activity decreased when ALA levels increased from 0 to $6 \%$, which is consistent with the results of previous studies (Herbert et al., 1980; Manning et al., 2007), but interestingly, when the amount of ALA continued to increase to 8 and $10 \%$, the lipase activity increased rapidly. Currently, no reports are consistent with this finding. We believe that the level of added fatty acids may be too high, causing intestinal inflammation in the bees, and thus, highly elevated lipase activity. For this reason, we recommend that the amount of fatty acids added to substitution pollen should not exceed $6 \%$ to prevent negative effects on bee health.

The population of a bee colony can be used to measure the strength of the colony and is also an estimated indicator of bee nutritional needs (Li et al., 2005). Feeding the bees pollen or pollen substitute during the spring breeding stage may alleviate the diet reserve shortage of bees in the spring. It may also prompt many queen spawnings, and ensure the rapid growth of the colony. In this experiment, the population of the bee colony rose slowly at the beginning and then rose more rapidly. This result is inconsistent with the findings of DeGrandi-Hoffman et al. (2008) and Feng et al. (2011). Maybe the inconsistency was caused by the different test times. The importance of lipids in the diet of honey bees was previously demonstrated by Herbert et al. (1980), who showed that bee colonies fed $2,4,6$, or $8 \%$ lipids reared more broods to the sealed stage than did colonies fed only the pollen substitute without the lipids. In our experiment, colonies fed 2, 4, or 6\% ALA in the pollen substitute, had increased bee populations and sealed broods, compared with those of the control group.

The emergence weight of workers was an important indicator of the quality of individual bees (Cheng et al., 2008). In this experiment, the emergent weights of workers in the 4 and $6 \%$ ALA groups were significantly higher than those in the 2 and $10 \%$ groups. Relative to the control group, the emergent worker bee weights of the $4 \%$ group and 6\% group showed a 7.12 and $5.57 \%$ increase, respectively, indicating that ALA affected the emergent weight of the workers.

Longevity is an important indicator of the quality of pollen or pollen substitutes (Schmidt et al., 1987) and is also an important factor that affects the development of the colony and colony productivity. Because of different seasons, the average life expectancy 
of bees varied greatly under outdoor conditions. Measuring the effect of diet on the longevity of bees in the laboratory allowed for a controlled environment with less variability in the average life expectancy. Many studies have demonstrated that dietary fatty acid levels are closely related to honey bee longevity. A study by Manning et al. (2007) found that diets high in oleic acid significantly reduced the life of bees. This finding may possibly be because the high oleic acid diet was toxic to bees, and diets high in linoleic acid also reduced the lifespan of bees. When full-fat soy flour and defatted soybean meal were fed to bees, the bees tended to feed on the defatted soy flour and have a high survival rate. Diets supplemented with $2 \sim 6 \%$ ALA can increase the lifespan of bees, as seen in Fig. 2. This increase may be related to the ability of ALA to enhance immunity. Ihle et al. (2014) found that workers lived longest on a diet high in carbohydrates and low in protein and lipids. Some studies have shown that high concentrations of ALA in bee pollen and in the bee gut can prevent bacterial (Manning, 2001) and fungal (Pandey et al., 1983) infections, enhance bee gut health, and prolong the life of bees. As shown in Fig. 1, bees in the $2 \sim 6 \%$ ALA groups had higher birth weights, which were more closely related to the relationship between the verified birth weight and lifespan of the bees. These results show that the amount of dietary ALA added cannot exceed $8 \%$; otherwise, ALA is toxic to the bees, reducing the lifespan of the bees.

\section{CONCLUSIONS}

In our study, the feeding amounts of the bee colony, colony population, sealed brood amount, and the weight of newly emerged workers were significantly affected by ALA levels in pollen substitute. Alpha-linolenic acid is one of the nutrients, which can keep colony-development rapid and healthy. Alpha-linolenic acid levels of $2 \sim 4 \%$ of the pollen substitute were optimal for maintaining the highest reproductive performance and the digestion and absorption of fatty acids in honey bees during the period of spring growth. Additionally, ALA levels of 2 $\sim 6 \%$ of the pollen substitute, prolonged the life of the worker bee.

\section{ACKNOWLEDGMENTS}

This work was financially supported by the earmarked fund for the China Agriculture Research System (No. CARS-45) and Shandong Province Agricultural Fine Varieties Breeding Projects (20142016).

\section{REFERENCES}

Afik O., Dag A., Kerem Z., Shafir S. (2006) Analyses of avocado (Persea americana) nectar properties and their perception by honey bees (Apis mellifera). Journal of Chemical Ecology 32: 1949-1963.

Barker R. J., Lehner Y. (1 972) Free amino-acids in thoraces of flown honey bees, Apis mellifera L. (HymenopteraApidae). Comparative Biochemistry and Physiology Part B: Comparative Biochemistry 43: 163-169.

Black J. (2006) Honeybee nutrition: review of research and practices. Rural Industries Research and Development Corporation. Canberra. 271 pp.

Cheng Y. H., Liu Y. A., Hu F. L., Zheng H. Q., Jin S.H. (2008) Effect of protein nutritional levels on emergent weight and hypopharyngeal gland development of worker bee. Apiculture of China 59(12): 11-13.

DeGrandi-Hoffman G., Wardell G., Ahumada-Segura F. Rinderer T., Danka R., Pettis !. (2008) Comparisons of pollen substitute diets for honey bees: consumption rates by colonies and effects on brood and adult populations. Journal of Apicultural Research 47(4): 265-270.

De Groot A. P. (1 953) Protein and amino acid requirements of the honeybee (Apis mellifica L.). Physiologia Comparata et Oecologia 3: 197-285.

Dobson H. E. M. (1988) Survey of pollen and pollenkitt lipids - chemical cues to flower visitors. American Journal of Botany 75(2): 170-182.

Farrar C. L. (1934) Bees must have pollen, Glean. Bee Cult 62: 276-278

Feldlaufer M. L., Knox D. A., Lusby W. R., Shimanuki $H$. (1983) Antimicrobial activity of fatty acids against Bacillus larvae, the causative agent of American foulbrood disease. Apidologie 24: 95-99. 
Feng Y. (2002) Animal nutrition. Chinese Agricultural Press. Beijing. 325 pp.

Feng Q. Q., Xu B. H., Li C. C., Yang W. R. (201 1) Effects of vitamin $A$ on bee population, sealed brood quantity and antioxidant of Apis mellifera ligustica. Journal of Animal Nutrition 23(6): 971-975.

Hendriksma H. P., Oxman K. L., Shafir S. (2014) Amino acid and carbohydrate tradeoffs by honey bee nectar foragers and their implications for plant-pollinator interactions. Journal of Insect Physiology 69: 56-64.

HerbertE. W., ShimanukiH. (1978a) Chemical composition and nutritive-value of bee-collected and bee-stored pollen. Apidologie 9: 33-40.

Herbert E. W., Shimanuki H. (1978b) Consumption and brood rearing by caged honeybees fed pollen substitutes fortified with various sugars. Journal of Apicultural Research 17: 27-31.

Herbert E. W., Svoboda J. A., Thompson M. J., Shimanuki H. (1980) Sterol utilization in honey bees fed a synthetic diet: Effects on brood rearing. Journal of Insect Physiology 26: 287-289.

Hornitzky M. (2003) Fatty acids - an alternative control strategy for honeybee diseases. RIRDC Publication No. 03/028. Rural R\&D Corporation. Canberra, Australia. 735-736pp.

House H. L. (1961) Insect nutrition. Annals Review. Entomologist 6: 13-26.

Ihle K. E., Baker N. A., Amdam G. V. (2014) Insulin-like peptide response to nutritional input in honey bee workers. Journal of Insect Physiology 69: 49-55.

Jouanin L. (2000) Long-term effects of soybean protease inhibitors on digestive enzymes, survival and learning abilities of honey bees. Entomologia Experimentalis et Applicata 95: 21-29.

Kim Y. S., Smith B. H. (2000) Effect of an amino acid on feeding preferences and learning behavior in the honey bee, Apis mellifera. Journal of Insect Physiology 46: 793801.

Kinsella J. E. (1991) Advances in food and nutrition research. Vol. 33. Academic Press. London. 101 pp.
Li C. C., Xu B. B., Wang Y., Feng Q. Q., Yang W. R. (2012) Effects of dietary crude protein levels on development, antioxidant status, and total midgut protease activity of honey bee (Apis mellifera ligustica). Apidologie 43: 576 586.

Li J. L., Wang Z., Ding Y. B. (2005) Effect of pollen fed in different way on breeding of colony in spring. Apicultural Science and Technology 3: 2-4.

Loidl A., Crailsheim K. (2001) Free fatty acids digested from pollen and triolein in the honeybee (Apis mellifera carnica Pollmann) midgut. Journal of Comparative Physiology B 171: 313-319.

Manning R. (2001) Fatty acids in pollen: a review of their importance for honey bees. Bee World 82: 60-75.

Manning R., Rutkay A., Eaton L., Dell B. (2007) Lipidenhanced pollen lipid-reduced flour diets and their effect on the longevity of honey bees (Apis mellifera L.). Australian Journal of Entomology 46: 251-257.

Mersmann H. J., Houk J. M., Phinney G., Underwood M. C., Brown L. J. (1973). Lipogenesis by in vitro liver and adipose tissue preparations from neonatal swine. American Journal of Physiology 224(5): 1123-1 129.

Nation J. L. (2001) Insect physiology and biochemistry. CRC Press. Boca Raton, Florida. 485 pp.

Pandey D. K., Tripathi R. N., Tripathi R. D., Dixit S. N. (1983) Fungi toxicology in pollen grains. Grana 22: 31-33.

Paoli P. P., Donley D., Stabler D., Saseendranath A., Nicolson S. W., Simpson S. J., Wright G. A. (2014) Nutritional balance of essential amino acids and carbohydrates of the adult worker honeybee depends on age. Amino Acids 46: 1449-1458.

Pernal S. F., Currie R. W. (2000) Pollen quality of fresh and 1-year-old single pollen diets for worker honey bees (Apis mellifera L.). Apidologie 31: 387-409.

Pirk C. W. W., Boodhoo C., Human H., Nicolson S. W. (2009) The importance of protein type and protein to carbohydrate ratio for survival and ovarian activation of caged honeybees (Apis mellifera scutellata). Apidologie 41:62-72.

Ritz B. W., Gardner E. M. (2006) Malnutrition and energy restriction differentially affect viral immunity. Journal of Nutrition 136(5): 1141-1144. 
Saa-Otero M. P., Díaz-Losada E., Fernández-Gómez E. (2000) Analysis of fatty acids, proteins and ethereal extract in honeybee pollen - considerations of their floral origin. Grana 39: 175-181.

Saffari A. M., Kevan P. G., Atkinson J. L. (2004) A promising pollen substitute for honey bees. American Bee Journal 144(3): 230-231.

Sahiler N., Sahin A., Kaya S. (2003) The effect of supplementary feeding on honeybee colony performance. In: The XXXVI|Ith International Apicultural Congress of Apimondia. Ljubljana-Slovenia. 24-29 August 2003: 158.

SAS Institute, 2003. SAS/STAT User's Guide: Version 9.1 th edn.

Schmidt J. O., Thoenes S. C., Levin M. D. (1987) Survival of honey bees, Apis mellifera (Hymenoptera: Apidae), fed various pollen sources. Annals of the Entomological Society of America 80(2): 176-183.

Seeley T. D., Visscher P. (1985) Survival of honeybee in cold climates: the critical timing of colony growth and reproduction. Ecological Entomology 10(1): 81-88.
Somerville, D. (2000). Honey bee nutrition and supplementary feeding. Agnote DAI/178. NSW Agriculture: 1034-6848.

Standifer L. N. (1980) Honey bee nutrition and supplemental feeding. Agriculture Handbook Number 335: 39-45. Available at: http://www.beesource.com/ resources/usda/honey-bee-nutrition-and-supplementalfeeding/

Steen.J.. M. (2007) Effect of homemade pollen substitute on honey bee colony development. Journal of Apicultural Research 46: 114-119.

Sudd, J. H. (1985). Anatomy of the honey bee, by R. E. Snodgrass. Cornell University Press Paperbacks. Physiological Entomology 10(2): 241-241.

Wang Y., Ma L. T., Xu B. H. (201 1) Necessity and strategy for studying the nutrient requirements of honeybee. Chinese Journal of Animal Nutrition 23(8): 1269-1272.

Weiner $C$. N., Hilpert A., Werner M., Linsenmair $K_{\text {. }} E_{\text {, }}$ Bluthgen N. (2010) Pollen amino acids and flower specialisation in solitary bees. Apidologie 41: 476-487. 